\title{
Improved DC Model and Transfer Functions for the Negative Output Elementary Super Lift Luo Converter
}

\author{
Faqiang Wang ${ }^{\dagger}$
}

\begin{abstract}
Negative output elementary super lift Luo converter (NOESLLC), which has the significant advantages including high-voltage transfer gain, high efficiency, high power density, and reduced output voltage/inductor current ripples when compared to the traditional DC-DC converters, is an attractive DC-DC converter for the field of negative DC voltage applications. In this study, in consideration of the voltage across the energy transferring capacitor changing abruptly at the beginning of each switching cycle, the improved averaged model of the NOESLLC operating in continuous conduction mode (CCM) is established. The improved DC model and transfer functions of the system are derived and analyzed. The current mode control is applied for this NOESLLC. The results from the theoretical calculations, the PSIM simulations and the circuit experiments show that the improved DC model and transfer functions here are more effective than the existed ones of the NOESLLC to describe its real dynamical behaviors.
\end{abstract}

Keywords: NOESLLC, Improved DC model, Improved small signal model, Stability

\section{Introduction}

As a key part for the DC switching power supply with negative output voltage, DC-DC converters with negative output voltage have been increasingly concerned by researchers and engineers. Up to now, many DC-DC converters with negative output voltage have been proposed and designed [1-7], such as Buck-Boost converter, Cuk converter, and so on. Among them, an attractive DC-DC converter for achieving the negative output voltage, referred to as the negative output elementary super lift Luo converter (NOESLLC), was proposed by Luo and Ye in 2003 [7]. For this NOESLLC, as indicated in [8], it has the significant advantages including high-voltage transfer gain, high efficiency, high power density, and reduced output voltage/inductor current ripples when compared to the traditional DC-DC converters. Hence, after this converter proposed, many researchers have focus on the modeling, analysis, control, and application of this NOESLLC [9-13]. For example, under assumption that the voltage across the energy-transferring capacitor is constant and equal to the input voltage in the whole switching period, $\mathrm{Li}$ and Chen investigated the NOESLLC operating in discontinuous conduction mode (DCM) and derived the voltage transfer gain depending on switching frequency, duty ratio, inductor, and load resistor [9]. Indu and Chamundeeswari utilized this NOESLLC to realize the maximum power point

$\dagger$ Corresponding Author: State Key Laboratory of Electrical Insulation and Power Equipment, School of Electrical Engineering, Xi'an Jiaotong University, Xi'an, China. (eecjob@126.com)

* State Key Laboratory of Electrical Insulation and Power Equipment, School of Electrical Engineering, Xi'an Jiaotong University, Xi'an, China.

Received: September 18, 2016; Accepted: December 12, 2016 tracking (MPPT) for photovoltaic system, and the results described that, under the given solar insolation and temperature, this converter can draw maximum power from the PV panel by adjusting its duty ratio [10]. Jayashree and Uma proposed the quasi resonant NOESLLC and indicated that it has low switching losses for its zero voltage switching which is suitable for aerospace applications [11]. Under assumption that the internal resistance of the source has been known, Chamundeeswari, Seyezhai and Arul Robin established the full-order averaged model and designed the sliding model controller for the NOESLLC [12]. Moreover, under assumption that the voltage across the energy-transferring capacitor is constant and equal to the input voltage in the whole switching period, Kumar and Jeevananthan established the reduced-order averaged model and designed the sliding model controller for the NOESLLC [13]. All the above results are helpful for the NOESLLC in practical applications.

Unfortunately, the previous results about the modeling and analysis of the NOESLLC have some drawbacks since the assumptions are a little unreasonable, such as the assumption in [12] means that the internal resistance of the source must be known, and the assumption in [13] means that the abruptly changing on the voltage across the energy-transferring capacitor has not been considered. As a result, the existed averaged models of the NOESLLC are not effective enough for describing its real DC and small signal dynamical behaviors. In other words, it is necessary to establish the improved DC model and transfer functions for the NOESLLC.

The rest of this paper is organized as follows. In section 2 , the circuit operation of the NOESLLC is briefly described and some glimpses from PSIM simulations are 
presented. Then, the improved averaged model of the NOESLLC operating in CCM is established, and the improved DC model and transfer functions are derived in section 3. In section 4, the current mode control is applied for the NOESLLC and the close-loop transfer function is derived. In section 5 , the comparisons are given to confirm the effectiveness of the derivations. Then, the hardware circuit is designed and the circuit experiments are presented for further validations. Finally, some concluding remarks and comments are discussed in section 7 .

\section{Circuit Operation and Some Glimpses}

The NOESLLC is shown in Fig. 1, and it consists of one power switch $\mathrm{Q}$, two diodes $\mathrm{D}_{1}$ and $\mathrm{D}_{2}$, one inductor $L$, one energy-transferring capacitor $C_{b}$, one output capacitor $C_{0}$ and one load resistor $R$. The power switch Q is driven by the PWM signal $v_{d}$ with the period being $T$ and the duty cycle being $d$. The input voltage is denoted by $v_{i n}$, the current through the inductor $L$ is denoted by $i_{L}$, and the voltages across the capacitors $C_{b}$ and $C_{0}$ are denoted by respective $v_{b}$ and $v_{0}$. It is assumed that the passive components, $L, C_{b}$ and $C_{0}$, are lossless and the effects of on-resistance of power switch $\mathrm{Q}$ and diodes $\mathrm{D}_{1}$ and $\mathrm{D}_{2}$ are neglected.

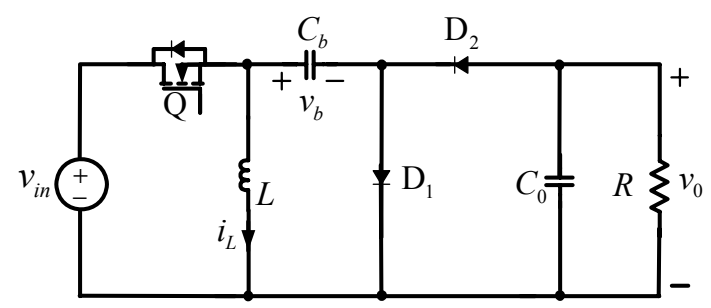

Fig. 1. Circuit schematic of the NOESLLC

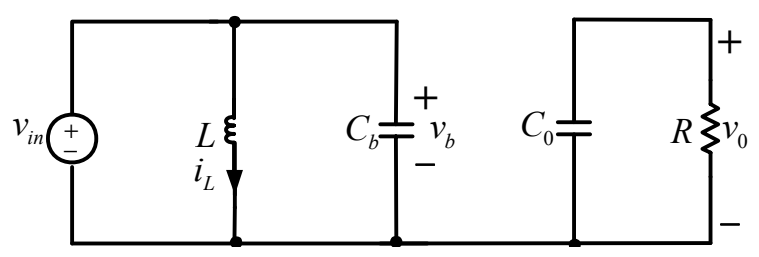

(a)

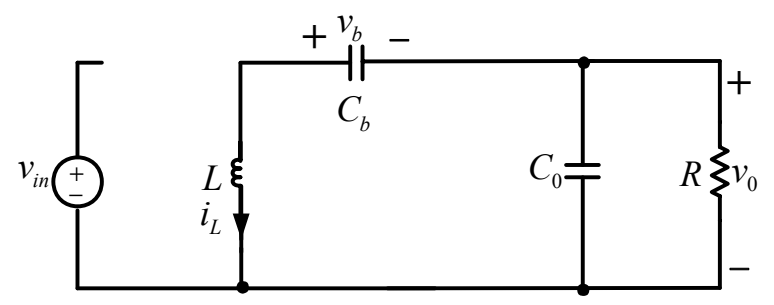

(b)

Fig. 2. Equivalent circuits for the NOESLLC operating in CCM: (a) Mode 1; (b) Mode 2.
As described in [7], there are two modes in the NOESLLC operating in CCM, and their respective equivalent circuits are shown in Fig. 2(a) (mode 1 within $(N T<t \leq(N+d) T)$ ) and Fig. 2(b) (mode 2 within $((N+d) T<t \leq(N+1) T)))$.

In mode 1 , the power switch $\mathrm{Q}$ and the diode $\mathrm{D}_{1}$ are turned on whereas the diode $\mathrm{D}_{2}$ is turned off since its biased voltage is inverse. As a result, the energy-transferring capacitor $C_{b}$ is charged by the input voltage $v_{i n}$ in very short duration of the time period, and immediately its voltage is equal to the input voltage $v_{i n}$. The inductor $L$ is magnetized and its current $i_{L}$ rises. The output capacitor $C_{0}$ supplies the energy to the load resistor $R$. The associated equations for the mode 1 can be established as follows.

$$
\left\{\begin{array}{l}
\frac{d i_{L}}{d t}=\frac{v_{i n}}{L} \\
\frac{d v_{0}}{d t}=-\frac{v_{0}}{R C_{0}} \\
v_{b}=v_{i n}
\end{array}\right.
$$

The equivalent circuit for the mode 2 is shown in Fig. 2(b) and the power switch $\mathrm{Q}$ and the diode $\mathrm{D}_{1}$ are turned off whereas the diode $\mathrm{D}_{2}$ is turned on. Hence, the inductor $L$ is demagnetized so that the inductor current $i_{L}$ falls, the energy-transferring capacitor $C_{b}$ is discharged and its voltage $v_{b}$ falls, and both of them provide the energy to the output capacitor $C_{0}$ and the load resistor $R$. The associated equations for the mode 2 can be given by

$$
\left\{\begin{array}{l}
\frac{d i_{L}}{d t}=\frac{v_{b}+v_{0}}{L} \\
\frac{d v_{0}}{d t}=-\frac{i_{L}}{C_{0}}-\frac{v_{0}}{R C_{0}} \\
\frac{d v_{b}}{d t}=-\frac{i_{L}}{C_{b}}
\end{array}\right.
$$

The circuit parameters are chosen as $v_{i n}=12 \mathrm{~V}, L=991 \mu \mathrm{H}$, $C_{b}=2.2 \mu \mathrm{F}, C_{0}=40 \mu \mathrm{F}, R=50 \Omega, D=0.4, f=20 \mathrm{kHz}$, and $T=1 / f$. Based on the PSIM software, the simulated results about the voltage $v_{b}$ and the PWM signal $v_{d}$ are shown in Fig. 3(a). The voltage $v_{0}$, the inductor current $i_{L}$ and the PWM signal $v_{d}$ are shown in Fig. 3(b). From (1), (2) and Fig. $3(\mathrm{a})$, it is obvious that the voltage $v_{b}$ equals $v_{0}$ within $N T<t \leq N T+d T$ while this case is not satisfied within $N T+d T<t \leq N T+T$. Thus, the assumption that the voltage $v_{b}$ is equal to $v_{0}$ in the whole switching period is a little unreasonable and unacceptable. This is why the existed averaged model of the NOESLLC in [13] dose not include the energy-transferring capacitor $C_{b}$. In the following sections, by considering that the abruptly changing on the voltage across the energy-transferring capacitor, the improved DC model and transfer functions of the 

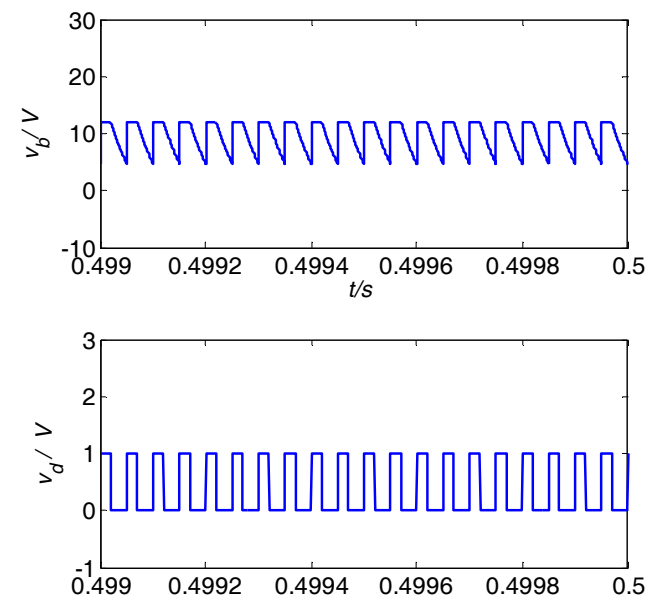

(a)
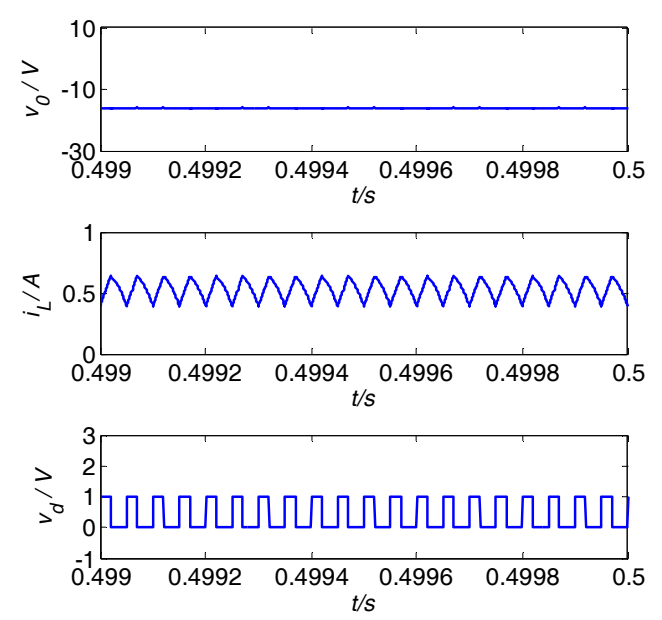

(b)

Fig. 3. PSIM simulations for the NOESLLC operating in CCM: (a) The voltage $v_{b}$ and the PWM signal $v_{d}$; (b) The voltage $v_{0}$, the inductor current $i_{L}$ and the PWM signal $v_{d}$

NOESLLC will be derived.

\section{Improved Averaged Model}

For convenience to establish the averaged model of the NOESLLC, some symbols are defined. $x$ is denoted by the circuit variables of the system, such as, $i_{L}, v_{0}, v_{b}, d$ and $v_{i n}$. $\langle x\rangle, X$, and $\hat{x}$ are defined as its averaged, DC, and small ac values, respectively. Also, the following items are assumed.

$$
\langle x\rangle=X+\hat{x} \quad \text { with } \quad \hat{x}<<X
$$

According to (1), (2) and using the averaging method [14-15], the averaged model of the NOESLLC can be expressed as follows.

$$
\left\{\begin{array}{l}
\frac{d\left\langle i_{L}\right\rangle}{d t}=\frac{\left\langle v_{i n}\right\rangle d+\left\langle v_{b}\right\rangle(1-d)+\left\langle v_{0}\right\rangle(1-d)}{L} \\
\frac{d\left\langle v_{0}\right\rangle}{d t}=-\frac{\left\langle i_{L}\right\rangle(1-d)}{C_{0}}-\frac{\left\langle v_{0}\right\rangle}{R C_{0}}
\end{array}\right.
$$

It is evident from (4) that the expression for the voltage $\left\langle v_{b}\right\rangle$ must be derived to get the complete averaged model for the NOESLLC operating in CCM.

Fortunately, from (1), (2) and Fig. 3(a), the expression for the voltage $\left\langle v_{b}\right\rangle$ can be easily calculated by using the geometrical relations.

$$
\left\langle v_{b}\right\rangle=\left\langle v_{i n}\right\rangle-a\left\langle i_{L}\right\rangle(1-d)^{2}
$$

where $a=1 /\left(2 f C_{b}\right)$.

Hence, the improved averaged model for the NOESLLC can be derived by substituting (5) into (4), and its result is

$$
\left\{\begin{array}{l}
\frac{d\left\langle i_{L}\right\rangle}{d t}=\frac{\left\langle v_{i n}\right\rangle}{L}-\frac{a\left\langle i_{L}\right\rangle(1-d)^{3}}{L}+\frac{\left\langle v_{0}\right\rangle(1-d)}{L} \\
\frac{d\left\langle v_{0}\right\rangle}{d t}=-\frac{\left\langle i_{L}\right\rangle(1-d)}{C_{0}}-\frac{\left\langle v_{0}\right\rangle}{R C_{0}}
\end{array}\right.
$$

Thereby, the DC equilibrium point of the NOESLLC can be calculated by taking (3) into (6) and then setting all the small signal items to be zero. The expression is

$$
\left\{\begin{array}{l}
I_{L}=\frac{V_{\text {in }}}{a(1-D)^{3}+R(1-D)^{2}} \\
V_{0}=-\frac{R V_{\text {in }}}{a(1-D)^{2}+R(1-D)}
\end{array}\right.
$$

From (7), one can see that both the DC values of the inductor current $i_{L}$ and the voltage $v_{0}$ are affected by not only the DC input voltage $V_{i n}$, the load resistor $R$ and the DC duty cycle $D$, but also the switching frequency $f$ and the energy-transferring capacitor $C_{b}$.

The small signal model of the NOESLLC operating in CCM can be derived by taking (3) into (6), and then removing the second and higher order small ac terms since their values are very small. The formula is

$$
\left\{\begin{array}{l}
\frac{d \hat{i}_{L}}{d t}=\frac{1-D}{L} \hat{v}_{0}-\frac{a(1-D)^{3}}{L} \hat{i}_{L}+\left(\frac{3 a I_{L}(1-D)^{2}}{L}-\frac{V_{0}}{L}\right) \hat{d}+\frac{\hat{v}_{i n}}{L} \\
\frac{d \hat{v}_{0}}{d t}=-\frac{(1-D)}{C_{0}} \hat{i}_{L}-\frac{1}{R C_{0}} \hat{v}_{0}+\frac{I_{L}}{C_{0}} \hat{d}
\end{array}\right.
$$

Consequently, using Laplace transform on (8) and the transfer functions' definitions, the input-to-inductor current transfer function $G_{i v}(s)$, the control-to-inductor current transfer function $G_{i d}(s)$, the control-to-output transfer function $G_{v d}(s)$ and the input-to-output transfer function 
$G_{v v}(s)$ of the NOESLLC can be derived as follows

$$
\begin{aligned}
& G_{i v}(s)=\left.\frac{\hat{i}_{L}(s)}{\hat{v}_{i n}(s)}\right|_{\hat{d}(s)=0}= \\
& \frac{s C_{0}+G}{s^{2} L C_{0}+s\left(L G+a C_{0}(1-D)^{3}\right)+(1-D)^{2}(1+a(1-D) G)} \\
& G_{i d}(s)=\left.\frac{\hat{i}_{L}(s)}{\hat{d}(s)}\right|_{\hat{v}_{i n}(s)=0}= \\
& \frac{\left(3 a I_{L}(1-D)^{2}-V_{0}\right) C_{0} s+(3 a(1-D) G+2) I_{L}(1-D)}{s^{2} L C_{0}+s\left(L G+a C_{0}(1-D)^{3}\right)+(1-D)^{2}(1+a(1-D) G)} \\
& G_{v d}(s)=\left.\frac{\hat{v}_{0}(s)}{\hat{d}(s)}\right|_{\hat{v}_{i n}(s)=0}= \\
& \frac{s I_{L} L+V_{0}(1-D)-2 a I_{L}(1-D)^{3}}{s^{2} L C_{0}+s\left(L G+a C_{0}(1-D)^{3}\right)+(1-D)^{2}(1+a(1-D) G)} \\
& G_{v v}(s)=\left.\frac{\hat{v}_{0}(s)}{\hat{v}_{i n}(s)}\right|_{\hat{d}(s)=0}= \\
& \frac{-(1-D)}{s^{2} L C_{0}+s\left(L G+a C_{0}(1-D)^{3}\right)+(1-D)^{2}(1+a(1-D) G)}
\end{aligned}
$$

From (9)-(12), it is obvious that the improved transfer functions are affected by the energy-transferring capacitor $C_{b}$. For example, when $C_{b}=1 \mu \mathrm{F}, 2 \mu \mathrm{F}, 4 \mu \mathrm{F}$ and $13 \mu \mathrm{F}$, the peak gains of $G_{i d}(s)$ equal $14.1 \mathrm{~dB}, 18.2 \mathrm{~dB}, 22.2 \mathrm{~dB}$ and $27.5 \mathrm{~dB}$, respectively. In other words, the peak gain of $G_{i d}(s)$ will increase with the value of the energy-transferring capacitor $C_{b}$ increasing.

\section{Current Mode Controlled NOESLLC}

The current mode control is applied for the NOESLLC. Its circuit schematic is shown in Fig. 4 and it consists of the current compensator and the PWM generator. Here, the current $i_{L}$ is transformed into the voltage with the same value by using the current sensor. The output voltage of the current compensator is defined as $v_{v f}$. The PWM signal $v_{d}$ can be generated by comparing the voltage $v_{v f}$ with the ramp signal $V_{\text {ramp }}$ whose expression is

$$
V_{\text {ramp }}=V_{L}+\left(V_{U}-V_{L}\right)\left(\frac{t}{T} \bmod 1\right)
$$

where $V_{L}$ and $V_{U}$ are the low and high threshold of the ramp signal $V_{\text {ramp }}$, respectively. $T$ is the switching period. The mathematical model for this current mode control can be given by.

$$
\frac{d d}{d t}=-\frac{R_{v f}}{R_{v d} V_{m}} \frac{d i_{L}}{d t}-\frac{i_{L}}{R_{v d} V_{m} C_{v f}}+\frac{v_{r e f}}{R_{v d} V_{m} C_{v f}}
$$

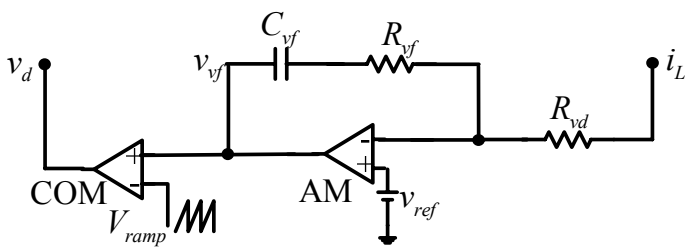

Fig. 4. The current mode control

By taking (3) into (14) and then separating DC and ac items, the following expressions can be obtained

$$
\begin{gathered}
I_{L}=V_{r e f} \\
\hat{d}(s)=-H(s) \hat{i}_{L}(s)
\end{gathered}
$$

where $H(s)=\frac{R_{v f}}{R_{v d} V_{m}}\left(1+\frac{1}{s R_{v f} C_{v f}}\right)$. Then, by combining (9), (10) and (16), the closed-loop transfer function of the current mode controlled NOESLLC can be derived and its result is

$$
G_{c i v}(s)=\frac{s^{2}+b s}{a_{11} s^{3}+a_{12} s^{2}+a_{13} s+a_{14}}
$$

where

$$
\begin{aligned}
b= & \frac{1}{R C_{0}}, \\
a_{13}= & \frac{1-D}{C_{0}}\left(1-D+\frac{I_{L} R_{v f}}{R_{v d} V_{m}}\right) \\
& +\left(3 a I_{L}(1-D)^{2}-V_{0}\right) \frac{R_{v f} C_{v f}+R C_{0}}{R C_{0} R_{v d} V_{m} C_{v f}}+\frac{a(1-D)^{3}}{R C_{0}} \\
a_{11}= & L a_{12}=\frac{L}{R C_{0}}+a(1-D)^{3}+\left(3 a I_{L}(1-D)^{2}-V_{0}\right) \frac{R_{v f}}{R_{v d} V_{m}}, \\
a_{14}= & \frac{I_{L}(1-D)}{C_{0} R_{v d} V_{m} C_{v f}}+\frac{3 a I_{L}(1-D)^{2}-V_{0}}{R_{v d} V_{m} R C_{0} C_{v f}} .
\end{aligned}
$$

Thus, the stability of the current mode controlled NOESLLC can be identified by observing the poles of (17). If all the poles are in the left side of the complex plane, it means that the system is in stable operation.

\section{Comparisons}

In order to confirm the effectiveness of the above derivations preliminary, the comparisons among the calculated results from the derived model here and the existed model in [13] and the PSIM simulations are carried out. Note that, the PSIM simulations about the bode diagrams are obtained from the switch model of the NOESLLC, not its averaged model, so that it can be used 


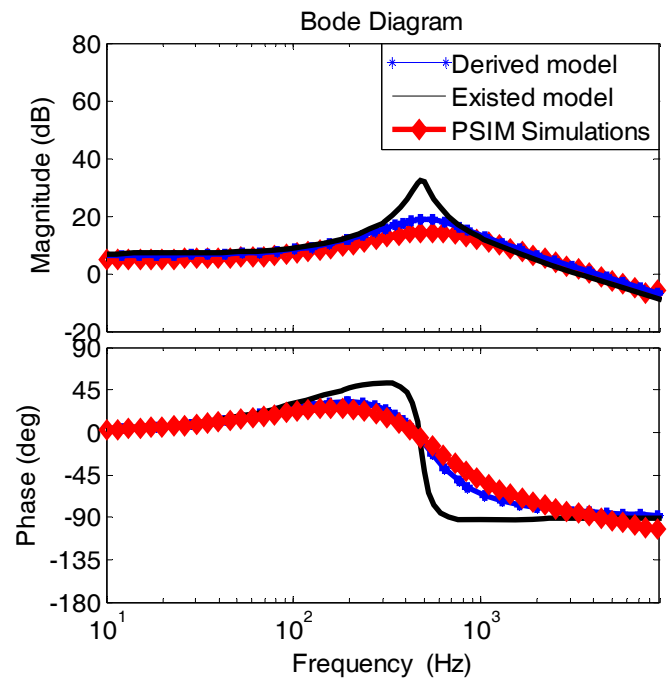

Fig. 5. Comparisons about the bode diagram of $G_{i d}(s)$ among the theoretical calculations from the derived model here and the existed model in [13], and the PSIM simulations

Table 1. The poles and zeroes of $G_{c i v}(s)$ under different values of the energy-transferring capacitor $C_{b}$

\begin{tabular}{cccccc}
\hline $\mathrm{C}_{\mathrm{b}}$ & $\lambda_{12}$ & $\lambda_{3}$ & $\mathrm{z}_{1}$ & $\mathrm{z}_{2}$ & State \\
\hline $8.0 \mu \mathrm{F}$ & $-227.6 \pm 16921.4 \mathrm{i}$ & -923.1 & -500 & 0 & Stable \\
$12.0 \mu \mathrm{F}$ & $-120.8 \pm 16709.4 \mathrm{i}$ & -936.2 & -500 & 0 & Stable \\
$16.0 \mu \mathrm{F}$ & $-65.87 \pm 16600.3 \mathrm{i}$ & -943.1 & -500 & 0 & Stable \\
$20.0 \mu \mathrm{F}$ & $-32.46 \pm 16534.3 \mathrm{i}$ & -947.4 & -500 & 0 & Stable \\
$24.0 \mu \mathrm{F}$ & $-9.965 \pm 16489.5 \mathrm{i}$ & -950.3 & -500 & 0 & Stable \\
$26.3 \mu \mathrm{F}$ & $-0.078 \pm 16469.8 \mathrm{i}$ & -951.6 & -500 & 0 & Stable \\
$26.4 \mu \mathrm{F}$ & $0.308 \pm 16469.2 \mathrm{i}$ & -951.6 & -500 & 0 & Unstable \\
\hline
\end{tabular}

to confirm the effectiveness of the derived transfer functions preliminary [16-18].

\subsection{Comparisons of transfer function in open-loop}

In practical applications, the precise of the transfer function is very important for consequently control design. Thus, it is necessary to validate the effectiveness of the derived transfer functions. Here, only the transfer function from inductor current to the duty cycle, that is $G_{i d}(s)$, is chosen as an example. Fig. 5 shows the calculated results from the derived model here and the existed model in [13] and the PSIM simulations. Obviously, the derived model here is more in good agreement with the PSIM simulations than the existed one.

\subsection{Stability of the current mode controlled NOESLLC}

The poles and zeroes of $G_{c i v}(s)$ under different values of the energy transferring capacitor $C_{b}$ can be calculated from (17) and presented in Table 1, and its pole-zero plot is shown in Fig. 6. Note that, the circuit parameters for the current mode controller are $R_{v d}=2.7 \mathrm{k} \Omega, v_{r e f}=0.7 \mathrm{~V}, R_{v f}=$

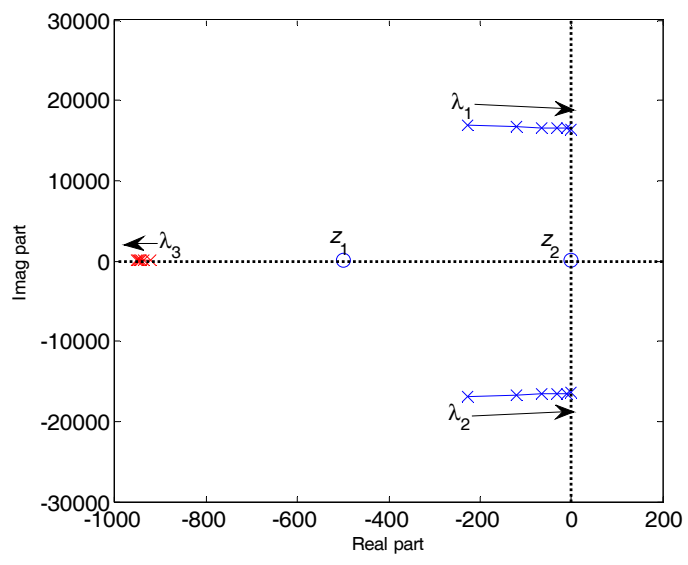

Fig. 6. The pole-zero plot of $G_{c i v}(s)$ under different values of the energy-transferring capacitor $C_{b}$
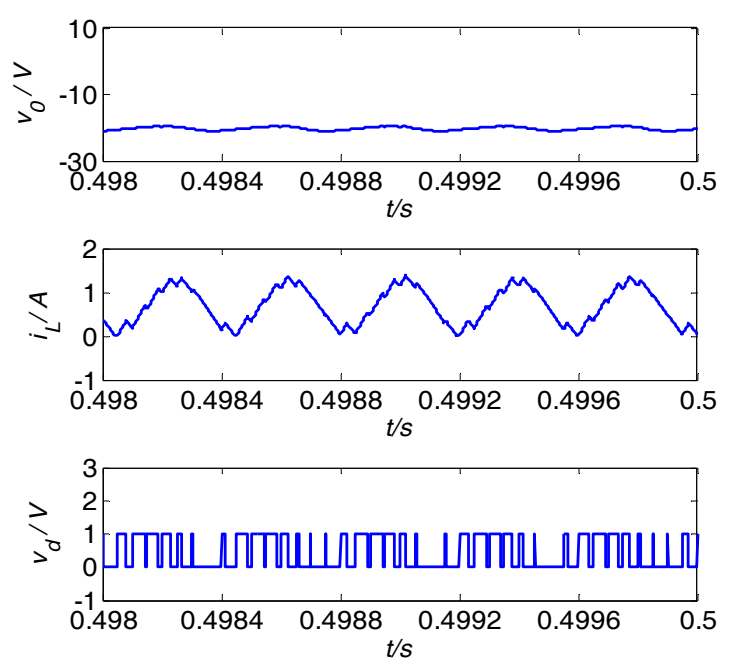

Fig. 7. Time-domain waveforms of the voltage $v_{0}$, the inductor current $i_{L}$ and the PWM signal $v_{d}$ for the current mode controlled NOESLLC from the PSIM simulations

$100 \Omega, C_{v f}=10 \mathrm{nF}$ and $V_{m}=3 \mathrm{~V}$. From Table 1 and Fig. 6 , it is found that the current mode controlled NOESLLC is prone to operate in unstable operation when the value of the energy-transferring capacitor $C_{b}$ increases. Specifically, if $C_{b} \leq 26.3 \mu \mathrm{F}$, the system is in stable operation. Otherwise, it is in unstable operation. For example, under $C_{b}=44.2 \mu \mathrm{F}$, the PSIM simulation results about the voltage $v_{0}$, the inductor current $i_{L}$ and the PWM signal $v_{d}$ for the system are shown in Fig. 7. Obviously, the system is really in unstable operation. However, from the existed model in [13], it is impossible to analyze the influence of the energytransferring capacitor $C_{b}$ on the system's stability since it is not included in the existed model.

\section{Circuit Experiments}

To validate the derivations and analyses further, the 


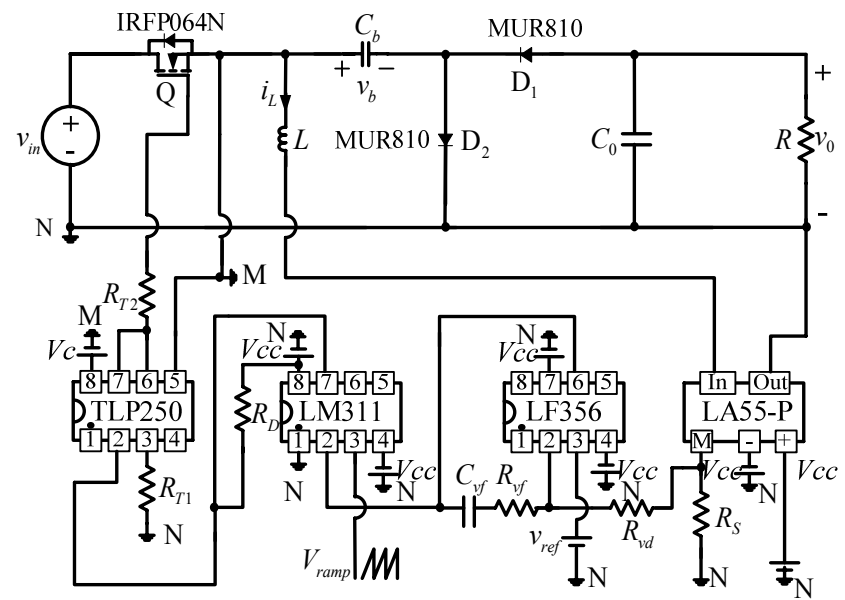

Fig. 8. Full schematic experimental circuit for the current mode controlled NOESLLC

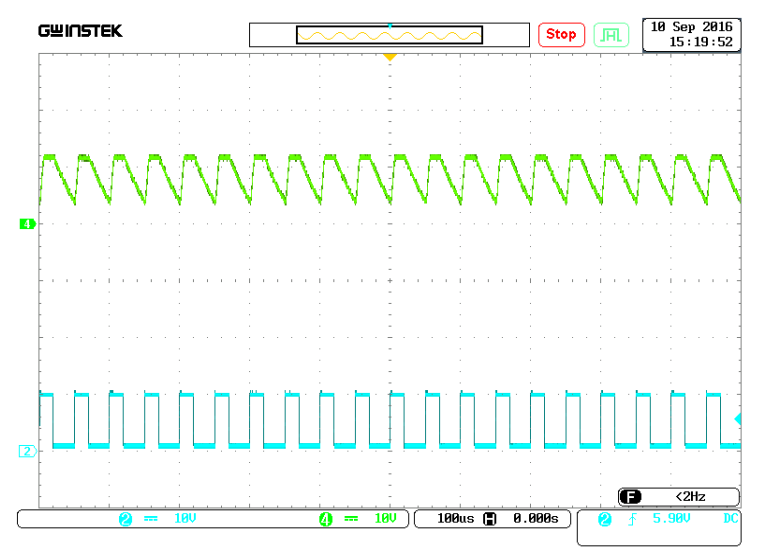

(a)

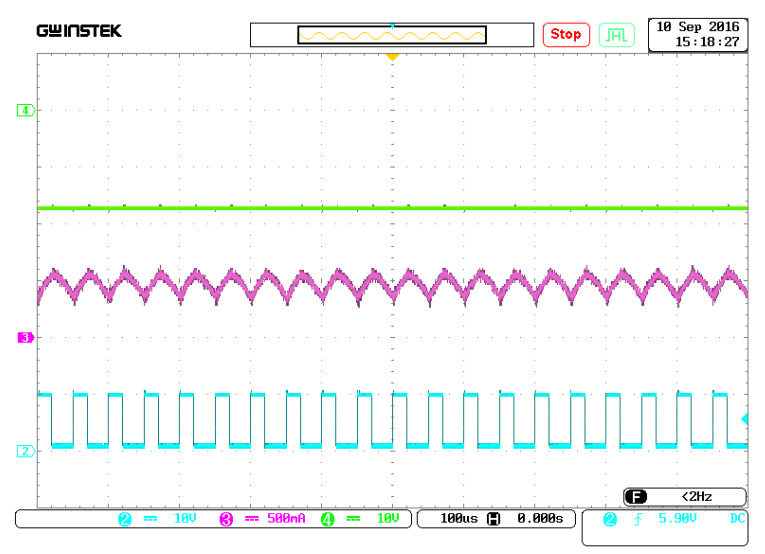

(b)

Fig. 9. Experimental time-domain waveforms for the NOESLLC in open loop (Time: $100 \mu \mathrm{s} / \mathrm{div}$ ): (a) The voltage $v_{b}$ (Upper: $10 \mathrm{~V} / \mathrm{div}$ ) and the PWM signal $v_{d}$ (Lower: $10 \mathrm{~V} / \mathrm{div}$ ); (b) The voltage $v_{0}$ (Upper: $10 \mathrm{~V} /$ div), the inductor current $i_{L}$ (Middle: $500 \mathrm{~mA} / \mathrm{div}$ ) and the PWM signal $v_{d}$ (Lower: $10 \mathrm{~V} / \mathrm{div}$ )

current mode controlled NOESLLC is designed by using the circuit components and integrated chips, and its full

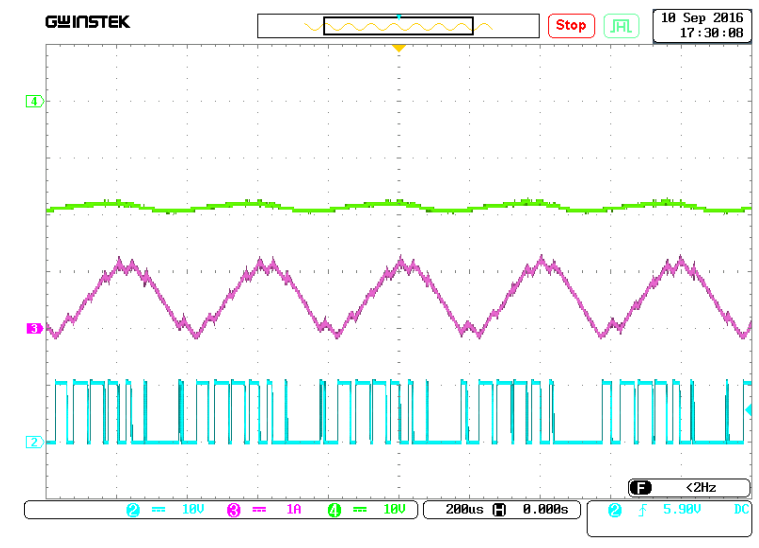

Fig. 10. Experimental time-domain waveforms for the voltage $v_{0}$ (Upper: $\left.10 \mathrm{~V} / \mathrm{div}\right)$, the inductor current $i_{L}$ (Lower: 1A/div) and the PWM signal $v_{d}$ (Lower: $10 \mathrm{~V} / \mathrm{div}$ ) for the current mode controlled NOESLLC under $C_{b}=44.2 \mu \mathrm{F}$ (Time: $200 \mu \mathrm{s} / \mathrm{div}$ )

schematic experimental circuit is shown in Fig.8. Note that, the power switch Q is realized by the MOSFET IRFP064N and driven by the PWM signal $v_{d}$ from the photocoupler TLP250. Diodes $D_{1}$ and $D_{2}$ are realized by MUR810. The current transducer LA55-P is used to measure the inductor current $i_{L}$. The JFET input operational amplifier LF356 is used to construct the current compensator. The voltage comparator LM311 is generally applied to generate the PWM signal $v_{d}$ by comparing the voltage $v_{v f}$ with the ramp signal $V_{\text {ramp }}$. In addition, the digital oscilloscope GDS 3254 is applied to capture the measured time-domain waveforms via the high voltage differential probe P5200A.

\subsection{Experiments for the NOESLLC in open-loop}

Under the given circuit parameters in section 2, the circuit experimental results for the NOESLLC in open loop are shown in Fig. 9. By comparing Fig. 9 with Fig. 3, one can see that they are in good agreement with each other and there really has the jump on the voltage across the energy-transferring capacitor $C_{b}$.

\subsection{Experiments for the current mode controlled NOESLLC}

Choosing $V_{C C}=15 \mathrm{~V}, V_{C}=15 \mathrm{~V}, R_{D}=510 \Omega, R_{T 1}=1.5 \mathrm{k} \Omega$, $R_{T 2}=15 \Omega$ and $R_{S}=100 \Omega$ for the current mode controller, the circuit experimental results under $C_{b}=44.2 \mu \mathrm{F}$ are shown in Fig. 10. From Fig. 10, it is easily seen that the current mode controlled NOESLLC is really operates in unstable operation. Also, for the unidirectional conductivity of the diodes, the voltage $v_{0}$ and the inductor $i_{L}$ can not be increased all the time so that the oscillation occurs and its oscillation frequency is smaller than the switching frequency $f$ and these are in good agreement with Fig. 7. Therefore, the energy-transferring capacitor really has an 
important influence on the stability of the current mode controlled NOESLLC.

\section{Conclusions}

By using the averaging method and in consideration of the abruptly changing on the voltage across of the energytransferring capacitor $C_{b}$, the improved averaged model of the NOESLLC converter operating in CCM is established. The DC model and transfer functions of the NOESLLC operating in CCM is derived and four types of transfer functions, that is, the input-to-inductor current transfer function $G_{i v}(s)$, the control-to-inductor current transfer function $G_{i d}(s)$, the control-to-output transfer function $G_{v d}(s)$ and the input-to-output transfer function $G_{v v}(s)$, are derived. The theoretical calculations from the derived model, the PSIM simulations and the circuit experiments are in good agreement with each other, and all of them describe that the improved DC model and transfer functions here are more effective than the existed ones for describing the real dynamical behaviors of the NOESLLC operating in CCM.

\section{Acknowledgements}

This work was supported by the National Natural Science Foundation of China (Grant no. 51377124), a Foundation for the Author of National Excellent Doctoral Dissertation of PR China (Grant no. 201337), the New Star of Youth Science and Technology of Shaanxi Province (Grant no. 2016KJXX-40).

\section{References}

[1] Y.K. Lo, J.T. Chen, C.Y. Lin, S.Y. Ou, "Improved Control-to-output Characteristics of a PWM Buckboost Converter," International Journal of Circuit Theory and Applications, vol. 39, pp. 203-209, 2011.

[2] B. Axelrod, Y. Berkovich, A. Ioinovici, "Switchedcapacitor/Switched-inductor Structures for Getting Transformerless Hybrid DC-DC PWM Converters," IEEE Transactions on Circuits and Systems-I: Regular Papers, vol. 55, no. 2, pp. 687-696, 2008.

[3] E. H. Ismail, M. A. Al-Saffar, A. J. Sabzali, A. A. Fardoun, "A Family of Single-switch PWM Converters with High Step-up Conversion Ratio," IEEE Transactions on Circuits and Systems-I: Regular Papers, vol. 55, no. 4, pp. 1159-1171, 2008.

[4] K. I. Hwu, Y. H. Chen, W. C. Tu, "Negative-output $\mathrm{KY}$ Boost Converter," Proceedings of the IEEE International Symposium on Industrial Electronics (IEEE ISIE '09), pp. 272-274, 2009.
[5] K. R. Kumar, S. Jeevananthan, "Analysis, Design, and Implementation of Hysteresis Modulation Slidingmode Controller for Negative-output Elementary Boost Converter," Electric Power Components and Systems, vol. 40, pp. 292-311, 2012.

[6] C. Krishnakumar, P. Muhilan, M. Sathiskumar and M. Sakthivel, "A New Random PWM Technique for Conducted-EMI Mitigation on Cuk Converter," Journal of Electrical Engineering \& Technology, vol. 10, no. 3, pp. 916-924, 2015.

[7] F. L. Luo, H. Ye, "Negative Output Super-lift Converters," IEEE Transactions on Power Electronics, vol. 18, no. 5, pp. 1113-1121, 2003.

[8] K. R. Kumar, S Jeevananthan, "Design and Implementation of Reduced-order Sliding Mode Controller Plus Proportional Double Integral Controller for Negative Output Elementary Super-lift Luo-converter," IET Power Electronics, vol. 6, no. 5, pp. 974-989, 2013.

[9] J. C. Li, H. Y. Chen, "Discontinuous Conduction Mode of Negative Output Elementary Circuit," Journal of Marine Science and Technology, vol. 12, no. 2, pp. 124-127, 2004.

[10] V. R. Indu, V. Chamundeeswari, "Design and Implementation of Maximum Power Point Tracking for Super Lift Converter," International Journal for Research and Development in Engineering, pp. 12-16, 2014.

[11] E. Jayashree, G. Uma, "Design and Implementation of Quasi Resonant-negative Output Super Lift Luo Converter," Journal of Electrical Engineering, vol. 10, pp. 127-134, 2010.

[12] V. Chamundeeswari, R. Seyezhai, A. Arul Robin, "Stabilization and Robustification of Negative Output Superlift Luo Converter using Sliding Mode Control Approach," International Journal of Advances in Engineering \& Technology, vol. 3, no. 2, pp. 508-519, 2012.

[13] K. R. Kumar, S. Jeevananthan, "Modelling and Implementation of Fixed Switching Frequency Sliding Mode Controller for Negative Output Elementary Super Lift Luo-converter," IET Power Electronics, vol. 5, no. 8, pp. 1593-1604, 2012.

[14] R. D. Middlebrook, S. Cuk, "A General Unified Approach to Modeling Switching-converter Power Stages," International Journal of Electronics, vol. 42, no. 6, pp. 521-550, 1977.

[15] M. G. Villalva, T. G. de Siqueira, E. Ruppert, "Voltage Regulation of Photovoltaic Arrays: Smallsignal Analysis and Control Design," IET Power Electroniccs, vol. 3, no. 6, pp. 869-880, 2010.

[16] N. Femia, M. Fortunato, G. Petrone, G. Spagnuolo, M. Vitelli, "Dynamic Model of One-cycle Control for Converters Operating in Continuous and Discontinuous Conduction Modes," International Journal of Circuit Theory and Applications, vol. 37, pp. 661-684, 
2009.

[17] M. R. D. Al-Mothafar, "On the Derivation of Control-to-output Voltage of PWM Current-Mode Controlled Modular DC-DC Converters: a PSIMSupported Proof," IEEE International Energy Conference, pp. 139-146, 2014.

[18] PSIM User's Guide, Version 9.0, Release 3, Powersim Inc. May 2010

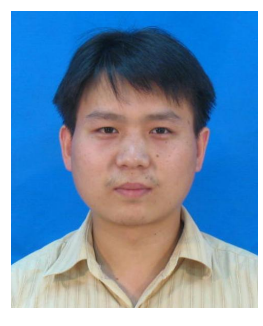

Faqiang Wang was born in China in 1980. He received his B.S. in Automation from Xiangtan University, Xiangtan, China, in 2003, and M.S. and Ph.D. in Electrical Engineering from Xi'an Jiaotong University, Xi'an, China, in 2006 and 2009, respectively. From 2009 to 2011, he was a lecture with School of Electrical Engineering, Xi'an Jiaotong University. Since 2011, he has been an Associate Professor in School of electrical Engineering, Xi'an Jiaotong University. His current research interests include modeling, analysis and control of power electronics. 